\title{
Use of Fluoridated Dentifrices among Children: Are We in the Right Direction?
}

\author{
Aditi Kapur $^{1} \quad$ J. S. Thakur ${ }^{2} \quad$ K. Gauba ${ }^{3} \quad$ A. Goyal ${ }^{1}$ \\ ${ }^{1}$ Pediatric Dentistry Unit, Oral Health Sciences Centre, \\ Postgraduate Institute of Medical Education and Research, \\ Chandigarh, India \\ ${ }^{2}$ Department of Community Medicine and School of Public Health, \\ Postgraduate Institute of Medical Education and Research, \\ Chandigarh, India \\ ${ }^{3}$ Department of Oral Health Sciences Centre, Postgraduate Institute \\ of Medical Education and Research, Chandigarh, India \\ ${ }^{4}$ Department of Community Dentistry, Oral Health Sciences \\ Centre, Postgraduate Institute of Medical Education and Research, \\ Chandigarh, India
}

Ann Natl Acad Med Sci (India) 2019;55:54-59

\author{
K. Mohit ${ }^{4} \quad$ J. Manoj ${ }^{1}$
}

\section{Abstract}

\section{Keywords}

- fluoride dentifrices use

- very young children

- trend
Introduction Use of topical fluorides in dentifrices has always been an important tool in prevention of dental caries in young children. Due to the easy availability of various low and high fluoride dentifrices, the parents have no clear understanding about their correct age-appropriate use in children. This study was undertaken to evaluate and understand the trend and current practices among the end user.

Materials and Methods A total of 173 children aged 4 to 6 years were enrolled in the study from schools located in two different geographical areas of the Chandigarh city; group $1(n=90)$ from a peri-urban slum cluster: (Govt. Primary School, Indira Colony, Mani Majra, $n=51$ ); Govt. Middle School, Mani Majra ( $n=39)$; group $2(n=83)$ from an urban private city school (Ankur, Punjab University, Sector 14) using cluster sampling method. Two examiners using type IV examination examined all the children aged 4 to 6 years present using a preinstructed close-ended questionnaire. Data were analyzed using SPSS Software Version 25 (SPSS Inc., Chicago, IL, United States).

Results The data regarding the knowledge of fluoride in pastes showed that $85 \%$ of the children were using high fluoride pastes, $10 \%$ were using nonfluoride pastes, and $5 \%$ were using low fluoride pastes. In group 1 , none of the users were aware about the benefits/risk of using fluoride toothpastes and only $22 \%$ were aware in group 2 . Only $27 \%$ of children in group 1 dispensed the correct amount of dentifrice for this age group i.e., a pea head size versus $67 \%$ in group 2; a half brush length was dispensed by $61.5 \%$ in group 1 and $28 \%$ in group 2, and just a smudge by $11.5 \%$ in group 1 and $5 \%$ in group 2 . Forty one percent children in both the groups had a history of having intentionally consumed the toothpaste. The toothpaste was dispensed to the child by parent in $89 \%$ of cases in group 2 and only $50 \%$ in group 1 and $88 \%$ parents claimed to always supervise the child while tooth brushing versus only $53 \%$ in group 1 . Majority of the respondents', i.e., $97 \%$ in group 1 and $63 \%$ in group 2 had never been explained about the correct method of use of fluoride paste in children.

Conclusion Knowledge about fluoridated toothpastes is low among the population. The children in peri-urban slums areas are exposed to the high fluoride pastes from 
very early in life and there is no other toothpaste which is brought home except for those which are commonly used among the members. In the city schools; however, a small percentage of population uses low fluoride pastes in children, possibly due to a greater awareness and access to information, but has no clear idea about their limitations and benefits of age-appropriate use. Till appropriate guidelines are available for the country, a safe practice to follow is tailoring individual need based protocol. The children in peri-urban slums areas need to be educated more on the health practices and importance of use of fluoride dentifrices and the children in the city schools need to be guided more on the age appropriate use of high and low fluoride dentifrices.

\section{Introduction}

Prevention of oral diseases is an important aspect of Pediatric Dentistry. Topical fluorides from water, dietary sources, professional applications, etc. have a well-proven role in prevention and progression of dental caries in children. ${ }^{1}$ Dentifrices are the most widely used source of topical fluorides for children and have caused the largest impact on oral health, since their inception in early 1960s. Fluoride in the dentifrices acts by decreasing the rate of enamel demineralization and by enhancing the remineralization of an early carious lesion., ${ }^{2,3}$ Presence of fluoride in the tooth also increases the resistance of the remineralized areas to secondary acid attack. ${ }^{2,3}$ The use of fluorides in dentistry, however, has always been considered a two- edged sword with the cariostatic effect of fluoride being well proved, but not without the risk of causing fluorosis in the developing dentition. ${ }^{4-6}$ When used in very young children with the rising incidence of early childhood caries (ECC), fluoride as a preventive modality of dental caries, however, has become indispensable because of its cost effectiveness. $^{7}$

Fluoride as a mineral is required in our body in very low quantities of around 0.05 to $0.07 \mathrm{mg} / \mathrm{kg}$ body weight to exert its desirable effects. ${ }^{8}$ The risk of fluorosis occurs when the amount of fluoride ingested exceeds the amount required during tooth formation/development. ${ }^{4}$ An inadvertent consumption of fluoridated toothpastes in a young child with developing teeth has been associated with mild fluorosis as it remains an important source of ingested fluoride., ${ }^{9,10}$

To prevent these sequelae, and also to deliver the benefit of fluoride to children, low fluoride pastes with concentration of fluoride almost half or one fourth of that present in most conventional pastes had been devised and marketed. ${ }^{11-15}$ The different guidelines have taken the safety issues in consideration but concerns however, have been raised regarding the questionable efficacy of these low fluoride pastes. ${ }^{16-19}$

With the easy availability and marketing of various low and high fluoride toothpastes in the market ${ }^{20}$ one does not know the current practices among the end user, which is helpful in formulating new guidelines or reinforcing the current ones. This study was undertaken to evaluate and understand the trend among 4 to 6 years old children regarding use of fluoride pastes in the city.

\section{Materials and Methods}

A total of 173 children aged 4 to 6 years were enrolled in the study from schools located in two different geographical areas of the Chandigarh city; group $1(n=90)$ from a peri-urban slum cluster: (Govt. Primary School, Indira Colony, Mani Majra, $n=51$ ); Govt. Middle School, Mani Majra $(n=39)$; group $2(n=83)$ from an urban private city school (Ankur, Punjab University, Sector 14) using cluster sampling method. Ethical clearance from the Institute's ethics committee was obtained prior to initiation of the study. The school authorities were contacted prior to any interaction with the children for their consent, and an appropriate time suitable for recording of the questionnaires in the presence of at least one parent was decided. Two examiners using type IV examination examined all the children aged 4 to 6 years present. The examiners were calibrated (A K. and M.K.) before the start of the study. A preinstructed close-ended questionnaire regarding the use and practices of fluoride paste among children including the routine oral health practices was prepared and with at least one parent of each child within the school premises.

Data were analyzed using SPSS Software Version 25 (SPSS Inc., Chicago, IL, United States). Chi-square analysis was used to find the significance of the cross tabulation of counts of two or more variables. Student $t$-test and analysis of variance was used to find the significance of the cross tabulation of a variable with the mean of another variable.

\section{Results}

The data recorded were mainly categorized as (1) routine oral health practices and (2) practices pertaining to the use of dentifrices ( - Table $\mathbf{1}$ ).

\section{Routine Oral Health Practices}

Majority of the children in group 1 either brushed their teeth only once daily (54\%) or were irregular brushers (34.4\%). Only $5.5 \%$ brushed twice daily and the remaining had not started brushing till now. Whereas in group 2, 79.4\% brushed at least once daily and $13.3 \%$ brushed twice daily. The irregular brushers were $7.3 \%$. Ninety-eight percent of children in group 2 were using the pediatric sized brush versus $72 \%$ 
Table 1 Distribution of parameters recorded pertaining to use of fluoride dentifrices among the two groups

\begin{tabular}{|c|c|c|c|}
\hline Questions & Group 1 responses & Group 2 responses & $p$-Value \\
\hline \multicolumn{3}{|l|}{ Q1. Frequency of tooth brushing } & \multirow[t]{5}{*}{$p<0.001$} \\
\hline Once daily & 49 & 66 & \\
\hline Twice daily & 5 & 11 & \\
\hline Thrice daily & 31 & 6 & \\
\hline Not started & 5 & 0 & \\
\hline \multicolumn{3}{|l|}{ Q2. Average sugar exposures per day } & \multirow[t]{4}{*}{$p<0.001$} \\
\hline Less than three times & 40 & 54 & \\
\hline $3-5$ times & 23 & 27 & \\
\hline More than 5 times & 22 & 2 & \\
\hline \multicolumn{3}{|l|}{ Q3. Has the child been introduced to dental floss? } & \multirow[t]{3}{*}{$p=0.075$} \\
\hline Never seen or heard & $84.2 \%$ & 84.14 & \\
\hline Aware & $15.8 \%$ & 15.84 & \\
\hline \multicolumn{3}{|l|}{ Q4. Type of toothbrush used } & \multirow[t]{4}{*}{$p<0.001$} \\
\hline Adult size & 15 & 2 & \\
\hline Pediatric size & 61 & 81 & \\
\hline Not specific & 9 & 0 & \\
\hline \multicolumn{3}{|l|}{ Q5. Type of toothpaste used } & \multirow[t]{6}{*}{$p<0.001$} \\
\hline Fluoridated & 56 & 71 & \\
\hline Non fluoridated & 12 & 3 & \\
\hline Low fluoride & 0 & 7 & \\
\hline Did not know & 11 & 0 & \\
\hline Do not use & 7 & 2 & \\
\hline \multicolumn{3}{|l|}{ Q.6 Are you aware about fluoridated toothpastes? } & \multirow[t]{3}{*}{$p<0.001$} \\
\hline No & 85 & 65 & \\
\hline Yes & 0 & 18 & \\
\hline \multicolumn{3}{|l|}{ Q7. Amount of toothpaste dispensed } & \multirow[t]{4}{*}{$p<0.001$} \\
\hline Half brush length or more & 48 & 23 & \\
\hline Pea head size & 21 & 54 & \\
\hline Just a smudge & 9 & 4 & \\
\hline \multicolumn{3}{|l|}{ Q8. Method of dispensing toothpaste } & \multirow[t]{5}{*}{$p<0.001$} \\
\hline Every time by parent & 39 & 72 & \\
\hline Parent/child & 18 & 8 & \\
\hline Child & 14 & 1 & \\
\hline By child under supervision & 7 & 0 & \\
\hline \multicolumn{3}{|l|}{ Q9. Is the child able to spit out after brushing? } & \multirow[t]{4}{*}{$p=0.067$} \\
\hline Yes, fully & 42 & 64 & \\
\hline Partially & 33 & 16 & \\
\hline Never tries/unable & 3 & 1 & \\
\hline \multicolumn{3}{|l|}{ Q10. Has the child ever intentionally consumed toothpaste? } & \multirow[t]{4}{*}{$p=0.421$} \\
\hline Do not know & 7 & 2 & \\
\hline Yes & 32 & 33 & \\
\hline No & 46 & 48 & \\
\hline
\end{tabular}


Table 1 (continued)

\begin{tabular}{|c|c|c|c|}
\hline Questions & Group 1 responses & Group 2 responses & $p$-Value \\
\hline \multicolumn{4}{|c|}{$\begin{array}{l}\text { Q11. Have you ever been explained the correct use of tooth- } \\
\text { paste by a health care provider? }\end{array}$} \\
\hline Yes & 1 & 9 & \multirow[t]{3}{*}{$p<0.001$} \\
\hline Other sources & 2 & 22 & \\
\hline No & 82 & 52 & \\
\hline \multicolumn{4}{|c|}{ Q12. Do you supervise your child while toothbrushing? } \\
\hline Always & 45 & 73 & \multirow[t]{3}{*}{$p<0.001$} \\
\hline Partially & 19 & 9 & \\
\hline Never, does on its own & 21 & 1 & \\
\hline
\end{tabular}

in group 1. Majority of children in group 1 had more than five times sugar intake per day (26\%) versus very few $(2.4 \%)$ in group 2. Twenty seven percent in group 1 and $32.5 \%$ in group 2 had sugar exposures between 3 to-5 per day. Sugar exposures less than three times a day were present in $47 \%$ in group 1 and 65\% in group 2 .

\section{Awareness of Dental Floss}

Only $15 \%$ of children in both the groups were aware of dental floss and knew it should be customarily used along with tooth brushing every day. This may be due to the fact that dental floss is not as well marketed as other oral hygiene aids in India and that there is a lack of awareness regarding dental floss among the general population. So, it can be recommended that dental flossing should be taught at school level.

\section{Types of Toothbrushes}

It was seen that around 71\% in group 1 and $97 \%$ of group 2 children uses pediatric size of tooth brush and $17 \%$ in group 1 and $2 \%$ in group 2 uses adult size tooth brush. It may be because of nonavailability or lack of knowledge among the parents; however, it should be kept in mind that such children become more prone to the trauma due to toothbrush injury.

\section{Practices Pertaining to Use of Dentifrices}

The data regarding the knowledge of fluoride in pastes showed that $85 \%$ of the children were using high fluoride pastes, $10 \%$ were using nonfluoride pastes, and 5\% were using low fluoride pastes. In the group 1 , none of the users were aware about the fluoride toothpastes and only $22 \%$ were aware in the group 2 . Only $27 \%$ of children in group 1 dispensed the correct amount of dentifrice for this age group i.e., a pea head

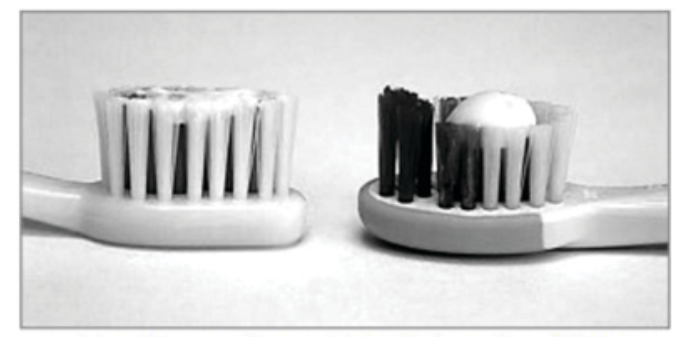

Fig. 1 The rice grain and pea head size of toothpastes. ${ }^{24}$ size versus 67\% in group 2; a half brush length was dispensed by $61.5 \%$ in group 1 and $28 \%$ in group 2, and just a smudge by $11.5 \%$ in group 1 and $5 \%$ in group 2 . Forty-one percent children in either group had a history of having intentionally consumed the toothpaste. The toothpaste was dispensed to the child by parent in $89 \%$ of cases in group 2 and in only $50 \%$ in group 1 and $88 \%$ parents claimed to always supervise the child while tooth brushing versus only 53\% in group 1 . Majority of the respondents' i.e., $97 \%$ in group 1 and $63 \%$ in group 2 had never been explained about the correct method of use of fluoride paste in children.

\section{Discussion}

Fluoride remains the cornerstone of the noninvasive management of noncavitated caries lesions and the use of fluoride toothpaste is generally recognized as the main reason for the decline in caries in industrialized countries over the last four decades. It is the only nonprescription toothpaste additive proven to prevent dental caries.

One of major concern in having fluoridated toothpaste in the vicinity of a young child is inadvertent ingestion leading to toxicity. Taking the average amount of toothpaste in a tube to be $100 \mathrm{~g}$, and the average amount of fluoride concentration to be $1,000 \mathrm{ppm}$ in our country (as per drug and cosmetic act, 1940), ${ }^{21}$ the total amount of fluoride, which is available, is $100 \mathrm{mg}(1,000 \mathrm{ppm}=1 \mathrm{mg} / \mathrm{g})$. The safely tolerated dose (STD) of fluoride is 8 to $16 \mathrm{mg} / \mathrm{kg}$ body weight. ${ }^{22}$ Taking the average body weight of a 5-year-old child to be $20 \mathrm{~kg}$, the STD is between than 160 to $320 \mathrm{mg}$ of fluoride, which remains in very safe limits. The probable toxic dose (PTD) is $5 \mathrm{mg} / \mathrm{kg}$ of body weight, ${ }^{22}$ that is $100 \mathrm{mg}$ of fluoride. The child, therefore, may show symptoms of toxicity only if almost the entire paste is inadvertently ingested. Second, there have been concerns about the occurrence of fluorosis in the permanent dentition due to early use of fluoride pastes. ${ }^{23}$ The American Academy of Pediatric Dentistry, therefore, recommends ${ }^{24}$ use of only a smudge or rice grain size $(- \text { Fig. } 1)^{24}$ of fluoridated paste $(0.125 \mathrm{~g})$ dispensed each time in children up to 3 years of age to reduce the risk of fluorosis due to ingestion of fluoride from the paste. For children up to 6 years of age, a pea size of the toothpaste is to be dispensed $(0.25 \mathrm{~g})$. These children ingest approximately 30 to $40 \%$ of the paste dispensed. 
The European Academy of Pediatric Dentistry recommends ${ }^{25}$ a use of pea size of $1,000 \mathrm{ppm}$ fluoride toothpaste $(0.25 \mathrm{~g})$ for children between 2 to- 6 years. Therefore, when using fluoridated toothpaste $(1,000 \mathrm{ppm})$ for a young child, if appropriate instructions are followed, there is minimal risk to the child of developing mild fluorosis or toxicity.

Overall, in this study, it is seen that knowledge about fluoridated toothpastes is low among the population. Some parents have not heard about the low fluoride pastes and avoid tooth brushing with pastes due to risk of ingestion, whereas others who have heard about the low fluoride pastes continue to use it even beyond two years and have no clear idea about when to stop its use. The children in peri-urban slums areas are exposed to the high fluoride pastes from very early in life and there is no other which is brought home except for those for common use among the members. In the city schools; however, a small percentage of population uses low fluoride pastes in children, possibly due to a greater awareness and access to information, but was found to have no clear idea about their limitations and benefits of age appropriate use. Lima et al. in a cross sectional observation study on tooth brushing habits of Brazilian schoolchildren aged 3 to-4 years found $42 \%$ children from high socioeconomic status (SES) and $2.7 \%$ children from low SES to be using toothpaste without fluoride or below $1000 \mathrm{ppm}$ fluoride. There was a lot of difference in the oral health practices between two groups in the present study. ${ }^{26}$ The number of sugar exposure children is quite high and knowledge about brushing twice daily and introduction to flossing still remains low. It is imperative, therefore, to guide the population about the need for an age appropriate use of fluoride pastes and also instruct them about their safe practice. The children in peri-urban slums areas need to be educated more on the health practices and importance of use of fluoride dentifrices and the children in the city schools need to be guided more on the age appropriate use of high and low fluoride dentifrices. One limitation of the study is that the toothpastes marketed without any known concentration of fluoride were recorded as fluoride free and actual fluoride levels in these tooth pastes were not assessed as this was beyond the scope of the present investigation.

\section{Conclusion}

Till appropriate guidelines are available for the country, a safe practice to follow is tailoring individual need based protocol. In a city like Chandigarh, where the water fluoride levels are only $0.3 \mathrm{ppm}$ and there is no other source of fluoride apart from the dietary fluoride, topical fluorides remain an important caries preventive tool. Since the risk of consumption is high till 2 years and the diet of the child is strictly under parental control reducing the number of sugar exposure, a low fluoride dentifrice can be used. Also, the most esthetically vulnerable teeth-the maxillary incisors, remain at a risk of being affected with enamel hypomineralization between 22 to 25 months. Beyond two years, the child undergoes individual choices about food, the risk of increased sugar exposure and more frequent snacking increases; a high fluoride paste with brushing under strict parental supervision is thus advisable.

\section{Conflict of Interest}

None declared.

\section{References}

1 Adair SM. Evidence-based use of fluoride in contemporary pediatric dental practice. Pediatr Dent 2006;28(2):133-142

2 Ericsson SY. Cariostatic mechanisms of fluorides: clinical observations. Caries Res 1977;11(Suppl 1):2-41

3 Duggal MS, Toumba KJ, Amaechi BT, Kowash MB, Higham SM. Enamel demineralization in situ with various frequencies of carbohydrate consumption with and without fluoride toothpaste. J Dent Res 2001;80(8):1721-1724

4 Ekambaram M, Itthagarun A, King NM. Ingestion of fluoride from dentifrices by young children and fluorosis of the teeth-a literature review. J Clin Pediatr Dent 2011;36(2):111-121

5 Wong MC, Glenny AM, Tsang BWK, Lo ECM, Worthington HV, Marinho VCC. Using a fluoridated supplement with a high fluoride concentration in children aged under 6 years may increase the risk of fluorosis. Evidence-based dentistry 2010;11(1):6-9

6 Kaminsky LS, Mahoney MC, Leach J, Melius J, Miller MJ. Fluoride: benefits and risks of exposure. Crit Rev Oral Biol Med 1990;1(4):261-281

7 Marinho VCC, Higgins JPT, Sheiham A, Logan S. Fluoride toothpastes for preventing dental caries in children and adolescents. Cochrane Database Syst Rev 2003; (1):CD002278

8 Farkas CS, Farkas EJ. Potential effect of food processing on the fluoride content of infant foods. Sci Total Environ 1974;2(4):399-405

9 Naccache H, Simard PL, Trahan L, et al. Factors affecting the ingestion of fluoride dentifrice by children. J Public Health Dent 1992;52(4):222-226

10 Bentley EM, Ellwood RP, Davies RM. Fluoride ingestion from toothpaste by young children. Br Dent J 1999;186(9):460-462

11 Beltrán ED, Szpunar SM. Fluoride in toothpastes for children: suggestion for change. Pediatr Dent 1988;10(3):185-188

12 Horowitz HS. The need for toothpastes with lower than conventional fluoride concentrations for preschool-aged children. J Public Health Dent 1992;52(4):216-221

13 Pessan JP, Alves KMRP, Ramires I, et al. Effects of regular and low-fluoride dentifrices on plaque fluoride. J Dent Res 2010;89(10):1106-1110

14 Ekambaram M, Itthagarun A, King NM. Comparison of the remineralizing potential of child formula dentifrices. Int J Paediatr Dent 2011;21(2):132-140

15 Thaveesangpanich P, Itthagarun A, King NM, Wefel JS. The effects of child formula toothpastes on enamel caries using two in vitro pH-cycling models. Int Dent J 2005;55(4):217-223

16 dos Santos AP, Nadanovsky P, de Oliveira BH. A systematic review and meta-analysis of the effects of fluoride toothpastes on the prevention of dental caries in the primary dentition of preschool children. Community Dent Oral Epidemiol 2013;41(1):1-12

17 Rasines G. Fluoride toothpaste prevents caries in children and adolescents at fluoride concentrations of $1000 \mathrm{ppm}$ and above. Evid Based Dent 2010;11(1):6-7

18 Ammari AB, Bloch-Zupan A, Ashley PF. Systematic review of studies comparing the anti-caries efficacy of children's toothpaste containing $600 \mathrm{ppm}$ of fluoride or less with high fluoride toothpastes of $1,000 \mathrm{ppm}$ or above. Caries Res 2003;37(2):85-92 
19 Freire IR, Pessan JP, Amaral JG, Martinhon CC, Cunha RF, Delbem AC. Anticaries effect of low-fluoride dentifrices with phosphates in children: A randomized, controlled trial. J Dent 2016;50:37-42

20 Dos Santos APP, de Oliveira BH, Nadanovsky P. A systematic review of the effects of supervised toothbrushing on caries incidence in children and adolescents. Int J Paediatr Dent 2018;28(1):3-11

22 Whitford GM, Fluoride toxicology and health effects. In Fejerskov O, Ekstrand J, Burt BA, eds. Fluorides in Dentistry. Hanover: International Society of Fluoride Resear ch1996;167-184

23 Wright JT, Hanson N, Ristic H, Whall CW, Estrich CG, Zentz RR. Fluoride toothpaste efficacy and safety in children younger than 6 years: a systematic review. J Am Dent Assoc 2014;145(2):182-189

24 American Academy of Pediatric Dentistry. Fluoride therapy. Pediatric Dentistry. Reference Manual 2018;40(6):250-253

25 European Academy of Paediatric Dentistry. Guidelines on the use of fluoride in children: an EAPD policy document. Eur Arch Paediatr Dent 2009;10(3):129-135

26 Lima CV, Pierote JJ, de Santana Neta HA, de Deus Moura de Lima M, de Deus Moura LdeF, de Moura MS. Caries, toothbrushing habits and fluoride intake from toothpaste by Brazilian Children according to socioeconomic status. Pediatr Dent 2016;38(4):305-310 